\title{
Smart and Tensed Beliefs
}

\author{
Vasilis Tsompanidis
}

Received: 30 December 2008 / Revised: 17 May 2009 /Accepted: 22 June 2009/

Published online: 18 July 2009

(C) The Author(s) 2009. This article is published with open access at Springerlink.com

\begin{abstract}
The aim of this paper is to defend a prototype B-theory answer to McTaggart's Puzzle about Time. Smart hopes to solve the issue by pointing to the "anthropocentricity" of temporal A-notions. There is one important problem: explaining Prior cases (for instance being relieved that a painful experience is over) in B-theoretic terms. First, it is argued that the problem is how to explain the nature of the subject's tensed belief in Prior cases; the essential indexicality of the concept 'now'. Then it is suggested that Smart could utilize Burge's framework for dealing with de re beliefs and a way of formalizing tensed beliefs is proposed. The last section of the paper deals with the exact role of the formalized indexical element. If these three steps are worked out, we might have an explanation of the facts involved in Prior cases without mentioning any A-facts. Hence an important problem to a Smart-influenced B-theory is solved, and McTaggart's Puzzle answered in an adequate manner.
\end{abstract}

Keywords Time $\cdot$ Tensed beliefs $\cdot$ Smart $\cdot$ Indexicals $\cdot$ Perry $\cdot$ Burge $\cdot$ Here $\cdot$ Now

1.

At the beginning of the 20th century, J. McTaggart presented the most prominent argument in twentieth century philosophy of time that purported to prove that time is unreal. According to McTaggart:

Positions in time, as time appears to us prima facie, are distinguished in two ways. Each position is Earlier than some and Later than some of the other positions. [...] In the second place, each position is either Past, Present, or Future. The distinctions of the former class are permanent, while those of the latter are not. If $M$ is ever earlier than $N$, it is always earlier. But an event, which is now present, was future, and will be past ${ }^{1}$.

These are the famous A-series and B-series notions, where the $A$-series of events is given by the descriptions "past," "present" and "future," while the $B$-series is

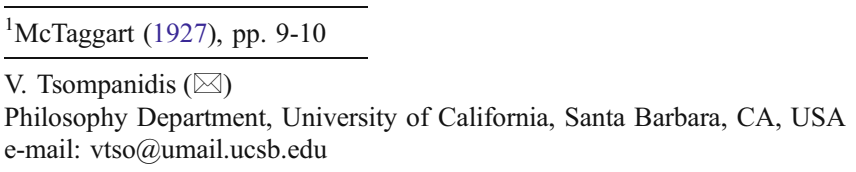


strictly in terms of the relational concepts "earlier", "later", as well as "simultaneous with". McTaggart's argument proceeds to claim:

(M1) there can be no time unless it has a dynamic element (that is, on his view, unless there is an A-series) and

(M2) there can be no A-series, because the supposition that there is an A-series leads to contradiction. Hence

(C) Time is unreal.

This is a very rudimentary formulation of McTaggart's claims, leaving out most of his arguments for M1 and M2. However, it is useful for the ensuing discussion, as the most usual way to block the conclusion is to deny one of the two premises. For instance, a B-theorist about time would use something like the following thesis to deny M1:

The B-property thesis: There are no genuine A-properties; talk that appears to be about the possession of A-properties by times, events or things can be correctly analyzed in terms of B-relations among those entities.

The additional details of McTaggart's arguments will not concern us at the moment. What will concern us is the answer to McTaggart's view of time given by J. J. C. Smart in his (1963) article "The Space-Time World". Smart disagrees with McTaggart's description of change in events and, consequently, (M1). He wishes to show that the A-series does not represent anything fundamental about the world as it is. In his view, the B-series is the primary and perfectly real one; he is the quintessential B-theorist.

Smart's starting point and overarching idea is that the A-notions are anthropocentric, in a way similar to the Aristotelian view of the universe that prevailed before the Copernican revolution in Astronomy. Let us present his positions as they are programmatically stated in the beginning of his paper (1963, p.295):

S1. A-notions have significance relative only to human thought and utterance. They do not apply to the universe as such.

S2. Tenses contain a similar hidden anthropocentricity.

S3. B-notions do not.

The following positions are also clearly stated in his (1963):

S4. The world is a four-dimensional continuum of space-time entities.

S5. There is no change in the actual world.

S6. Truth-conditional analysis: Take statement A: "e is happening now" uttered at $\mathrm{t}_{\mathrm{u}}$. Then an utterance $u$ of $\mathrm{A}$ is true iff e HAPPENS at $\mathrm{t}_{\mathrm{u}}$. Similarly for all tensed statements like A. \{verbs in capitals are tenseless

S7. Token Reflexivity: An utterance $u$ of 'now' means 'the time of this utterance', and an utterance of A means: 'e HAPPENS at the time of this utterance'. Similarly for all tensed statements like A.

S8. Eliminability of tense: Tenses of our ordinary language are to be analyzed away, since tensed sentences are equivalent to some 'tenseless' sentence.

Here is one interpretation of Smart's argument against M1: The token-reflexivity of tensed sentences (S7) plus the eliminability of tense (S8) leads almost straightforwardly to the position that present-ness (or past-ness or future-ness) is in the mind of the observer and could not exist without people or language. In this case there would be no utterances to fix the meaning of the term 'now', on which the notion of the past depends. 
This is how Smart thinks that he can reveal the hidden anthropocentricity of the A-series notions and hence support his S1 and S2. ${ }^{2}$ B-notions, on the other hand, do not have any such anthropocentricity (S3). And if S4 is correct, to describe the world as it really is (or, less strongly, as science depicts it), we do not need the A-series at all. Following claims S1 to S4, together with S5 (“"change' does not really exist"), McTaggart's argument can be seen as a pseudo-problem, and the notion of events changing (becoming past or present) as an illusion forced upon us by the inefficiency of ordinary language ${ }^{3}$. We seem to have an intuitive argument against McTaggart's (M1).

Do we need to buy all of Smart's positions to formulate a similar intuitive argument against (M1)? The worry is that some of them are not at all intuitive. For instance, the most unintuitive position that Smart presents is the eliminativist claim about change (S5). But the same argument would go through if we replaced (S5) with the slightly weaker perdurantist claim: (S5') change is just difference between time slices of four-dimensional solids. Similarly, even though claims (S2) and (S6) are quite plausible, it does not follow that it would be plausible to argue for a widely eliminativist view of tenses as meaningful constructs (Smart's S8). Besides being used widely by everyone, it looks like they also have significance towards our actions and, consequently, the world as a whole. I think therefore that the correct path of a B-theorist would be to try to explain tensed talk in some way and avoid, at least at the outset, the more extreme eliminativist position. But if we manage to explain tenses and temporal notions in a way that avoids using A-notions, while at the same time revealing in a different way their 'hidden anthropocentricity', we can keep Smart's (S1) and thereby retain his rejection of McTaggart's (M1). Similarly, even though his S7 has been widely attacked as a wrong theory about meaning, it is relevant only to the extent that Smart uses it to argue for the anthropocentricity of Anotions. So if we can replace it with a semantic theory about tenses that is free of token-reflexivity problems, ${ }^{4}$ and manage to reveal the anthropocentricity in a different way, we will have a steadier ground to argue for a B-theory of time.

\section{2.}

Even after these possible modifications, however, there is a set of cases describing concerns about time that escape Smart's easy classification as essentially involving only B-properties. Here are just two of them:

\section{Case 1 - the Prior Problem ${ }^{5}$ :}

I am getting off the dentist's chair after a particularly painful root canal. Being averse to pain, I am thinking the thought R: 'I am relieved that my root canal is over'.

\footnotetext{
${ }^{2}$ Tensed verbs contain the same anthropocentricity, as they can be seen as just coupling the verb's meaning with a specific A-notion.

${ }^{3}$ This is because (M1) suggests that we need the A-series to account for change in events.

${ }^{4}$ For instance we could use Salmon's (2003) theory about tenses that keeps tenseless propositions, thus giving Smart a step towards arguing for the anthropocentricity of tenses. I do not wish to indicate that this issue is an easy task- for instance I find Q. Smith's criticisms in his (1993) very persuasive. However, I think that in the best case these criticisms leave the issue unsettled, rather than delivering the mortal blow to the B-theorist.

${ }^{5}$ From Richard (2003) based on Prior's example in his (1959).
} 


\section{Case 2:}

I am an absent-minded graduate student who wakes up relatively late one morning for class. I am thinking the thought C: 'The class is starting now'. Consequently, I decide to run faster to catch the bus and the last part of the class.

In both cases I seem to use an A-notion to describe a feeling about an A-property (the past-ness of my root canal or the present-ness of my class start). A B-theory would have to explain how I come to have such an attitude if M1 is false and times cannot have A-properties. In case 2 the problem is more acute, as I seem to act on my belief, so there are robust consequences of a tensed belief that the B-theorist should explain without resorting to A-notions. The heirs of McTaggart in contrast could theorize that the action results from either a conscious deliberation on an A-fact or an apprehension of an A-property, thus having a first step to defend (M1). Hence, the B-theorist needs an explanation in both cases. Why am I relieved in case 1 ? Why do I run in case 2? Smart has a more particular problem since it looks like his S1 is in direct jeopardy: it appears that A-notions do in fact have significance relative to actions and thus the universe. He would thus need a B-theoretic explanation of both cases to argue that Anotions have significance relative only to human thought and utterance.

In a trivial sense the B-theorist can explain what is going on in these two cases by pointing to the tensed belief as the direct cause of my actions, as Mellor (1998) does. In case 1 , I am relieved because \{I believe that my root canal was over\}. In case $2, \mathrm{I}$ run because $\{\mathrm{I}$ believe that the class is starting now $\}$. I am very sympathetic to Mellor's account of the problem. The cause of the subject's action in Prior cases is uncontroversially the relevant belief that the subject has. This is not just a technical detail in the case; it is something that the A-theorist is forced to accept. Not only is this because there are complicated counterexamples where the action does not occur when the subject is seriously mistaken about the temporal order of things; it is because everyone would agree that in the absence of the relevant beliefs, the agent will not take the action she usually takes. Now the A-theorist cannot proceed to the strong claim that A-facts are required as causes of action in Prior cases. Even if Afacts existed in the world, the dialectic would go, an agent's action could be fully explained without mentioning them. I take it that this highlights an elementary and correct point: the primary cause of an action in a Prior case is an A-belief. ${ }^{6}$

However, Mellor's account is not satisfactory for the purposes of this paper.For one thing, a trivial explanation is not a full explanation at all. Even if we agree with Mellor's argument for the importance of tensed beliefs, what we absolutely need as B-theorists is a positive account of their emergence. In addition, we need a clear and correct explanation of the precise content of a true 'now'-belief (e.g. the belief, when true, that 'my class is starting now'). But Mellor does not give us such an account. In short, we

\footnotetext{
${ }^{6}$ This point might seem controversial because it is plausibly argued that reasons for acting in the straightforward cases are facts and not beliefs (for instance in Hyman 1999). But even under this view, beliefs are utilized to explain defective cases where the facts alone cannot explain the action taken; so if Afacts do not exist, we can still give a (now ubiquitous) belief-based explanation (I am indebted to Markos Valaris about this point). Moreover, I think that there might be some room to argue that there is a difference between reasons to act and direct causes of actions, which can be treated (per Davidson) as essentially belief and desire pairs, thereby pushing back the need of an A-fact.
} 
need a new argument to (i) explain the 'now-ish' part of the content of a tensed belief and (ii) reveal the hidden anthropocentricity of A-notions. We also have two overarching constraints: (i) our account should not use or involve A-notions and (ii) it should be consistent with, if not conducive to, Smart's main tenets (S1-S6).

It is clear that Smart's token-reflexivity analysis S7 will not help in explaining the situation, as I might not have uttered anything in any of the two cases. Since the meaning analysis of S7 centers in utterances, it cannot easily explain unuttered thoughts. Neither will a possible date-theoretic alternative analysis of the meaning of

$(\alpha)$ ' $e$ is happening now' $(\alpha$ '): 'e HAPPENS (at t)',

as something like

where (at $t$ ) would be any B-theoretic way to fill out the time of the 'happening' ${ }^{7}$ To see why, let us suppose in case 2 that I knew all along that my class starts at $\left(\mathrm{t}_{\mathrm{C}}\right)$ however we decide to cash out this time stamp. However, I didn't run until I thought C ('The class is starting now'). Similarly, I was not relieved that my root canal was earlier than a time $\left(t_{R}\right)$. We can even suppose that I knew all the relevant B-theoretic facts about my root canal. Intuitively, I was relieved only because it was over, i.e. in the past. It seems that in both cases I am having irreducibly tensed beliefs. More specifically, the relevant content of my beliefs that leads me to action (or relief) has an irreducibly tensed component.

It seems, however, that we can locate the source of our troubles in a single word: the word 'now'. For instance it seems straightforward that thought $\mathrm{R}$ is equivalent to thought R': 'I am relieved that my root canal was earlier than now'. Less strongly, at least the troubling aspect of the thought that we are trying to explain (the 'past-ness' of the root canal) is the same as in thought R'. If this is true, though, it looks like the problem could be formed in terms of beliefs containing indexical elements (since 'now' is one of them).

But there are well-known problems in the area of indexicals that look similar to the Prior problem. For instance we can have Perry's case of himself hearing "John Perry is making a mess" without necessarily apprehending that he is making a mess ${ }^{8}$ or the following:

\section{Case 3}

I am abducted from my house in Santa Barbara and end up, unbeknownst to me, in a house in Beverly Hills with no windows. Thankfully, I have Google Earth and plenty of time, so I spend my time learning all the spatial facts about the L.A. area. This does not help me when I escape though. It is only after I notice the Beverly Hills sign that I realize X: 'Thank goodness, my house is just a few miles north from here'.

\footnotetext{
$\overline{7}$ Tooley (1997), Oaklander (1994), Beer (1988) and Mellor (1998) have presented such a date-theoretic analysis of A-statements. I am not claiming here that these authors aim to provide an explanation of a true 'now'-belief (as the anonymous reviewer has remarked, their stated aim is only to account for its truth conditions). The more modest claim is rather that, were Smart to adopt such an account for his theory, he would still need to explain the Prior Problem in a different way.

${ }^{8}$ This is of course the classic example found in Perry (1979) p. 3
} 
Let's see how Perry is analyzing his case: "When we replace [the word 'I'] with other designations of me, we no longer have an explanation of my behavior, and so, it seems, no longer an attribution of the same belief. It seems an essential indexical"'. My suggestion is that in all four cases Perry's description applies: so we seem to have at least four essential indexicals. (in case 1 'earlier than now', in case 2 'now', in Perry's case 'I' and in case 3 'here'). Moreover, the problem the B-theorist faces is the same problem Perry acknowledges for the first person cases! Namely that, if we take the essentiality of the indexical to be a feature of the world, "we end up with a universe that has, in addition to our common world, myriads of private perspectives ${ }^{10}$ ". In the temporal case, this would mean that the temporal universe contains myriads of 'now' perspectives; and if that is true, McTaggart was right in asserting his M1, because we would need A-properties to describe the world. A Btheorist like Smart believes only in a common actual world: so the essentiality of the indexicals needs to be explained away (and their anthropocentricity somehow indicated) if we wish to argue against McTaggart's M1.

\section{3.}

The main idea I wish to put forward as an explanation of cases 1 and 2 is a possible completion of Mellor's view utilizing the framework of Tyler Burge's (1977) dealing with de re beliefs ${ }^{11}$. As defended by Burge in the case of perception in general, there is a sense in which a subject can have beliefs that encompass an indexical element, without that meaning that there is some "indexical thing" in the world that she is apprehending. In this case, the subject could have tensed beliefs (which was Mellor's main idea) without that meaning that she apprehends tensed facts (which would reinforce the need for A-properties and hence McTaggart's M1). ${ }^{12}$

Burge would like to ideally present an account of a de re belief that could differentiate between a similar de dicto belief. He suggests that a representation of

(4) Alfred believes the man in the corner to be a spy,

where we do not want to attribute to Alfred the notion of a man in the corner, should be something like

$\left(4^{\prime}\right)\left(\mathrm{B}_{\mathrm{r}}\left(\right.\right.$ Alfred, $<$ the man in the corner $>,\left\ulcorner\operatorname{Spy}(\mathrm{y})^{\urcorner}\right)$, where $\mathrm{B}_{\mathrm{r}}$ represents de re belief.

In this case the portion in $<>$ (angle) brackets serves to pick out that man and does not need to be "apprehended" by Alfred in order for him to entertain the belief. $\left(4^{\prime}\right)$ could be true regardless of Alfred's conceptual relations to the object. In this logical form, we can see exactly how the equivocation between de re and de dicto might take place. In a de dicto belief the subject is asserting a proposition, while in our case he is thinking of something that this something has a particular property.

\footnotetext{
${ }^{9}$ Perry (1979) page 16

10 ibid.

${ }^{11}$ In later works (e.g. 2003, 2005) Burge uses de se belief to deal with the same issues. Since de se belief is structurally similar to de re belief, and since it is not clear that the difference is vital for my account, I will stick to the earlier (1977) paper for the purposes of this paper.

12 There are of course many competing theories about indexicals, most notably Kaplan's (1989) and Perry's (2001). I believe that all of them fail to deal adequately with the Prior Problem, but a full explanation of my objections would strain the length of this paper.
} 
This is the lurking indexicality that is hidden sometimes in belief ascriptions and is indicated in our example by $(y){ }^{13}$

Burge proposes that something like this is probably happening in various cases (for instance most proper names) but he thinks that it is more pertinent with perception cases. ${ }^{14}$ Here is how Burge's story might explain case 3 in broad strokes: When I am seeing the Beverly Hills sign I am entertaining a thought with content (W): 'here lies a collection of wooden letters that look bright yellow' or I am apprehending some content that is close to that of thought W. At this moment I am having a thought formed by perceptual contact, whose content does not seem to include any explicit descriptive depiction of my own location in reference to the sign. More strongly, content (W) need not even be conceptual in Burge's analysis, since it is meant to encode the first, raw content of perception which could be non-conceptual. Back to our case 3, since I know from Google Earth that the only such sign is located in Beverly Hills I can entertain thought (L): "here is Beverly Hills" followed by thought $(\mathrm{X}),{ }^{15}$ as I know that Beverly Hills is some miles south of my house.

My suggestion is that one could use such a logical representation to describe what is going on in cases of temporal beliefs involved in Prior cases, as they can be seen as cases of perception, this time in the temporal realm. ${ }^{16}$ Let's see how this might apply to our case 2 . Suppose we have the agent $S$ with a tensed belief like the belief with content

(C) the class is starting now.

If we follow Burge, a logical representation of S's belief could very well be

\footnotetext{
${ }^{13}$ Burge's idea is that a free variable such as (y) corresponds rather naturally to a demonstrative element such as "this"; a feature that assigns a value depending on the context of the belief.

14 " $A$ de re belief is a belief whose correct ascription places the believer in an appropriate nonconceptual, contextual relation to objects the belief is about.[...]Perceptual contact [...] illustrates the sort of element independent of semantical or conceptual application that is essential to the notion." Burge (1977), pp. 346-7. Over the entire (1977) Burge indicates that temporal awareness has similar, if not the same, characteristics, see for instance p. 352. I agree with Burge's line of thought, assuming for the moment that time is a res and can be treated in such a way.

${ }^{15}$ I should note here that I am not explicitly talking about justification or entitlement to belief (X) - or (L) for that matter. For the purposes of this paper I will be content in explaining how the belief arises in normal subjects and normal circumstances. But I think that a similar story can explain justification issues if one is careful enough.

${ }^{16}$ As the anonymous reviewer has noticed, I probably owe the reader a precise account of the "tensed belief' I am trying to explain here as 'de re'. In this section I am primarily concerned with beliefs involved in Prior cases; and I think that those beliefs can be seen as incorporating an explicit temporal indexical notion like 'now'. What this treatment is definitely not about, is any belief that can be expressed in language by using a tensed statement. One reason is that such cases might cover the entire class of belief if indeed the use of tenseless verbs is as problematic as many people have thought. A related second reason is that some beliefs expressed with tensed statements do not involve any reference to times (examples include my belief that 2 plus 2 equals 4 , my belief that roses smell nice, or even my belief that drivers in England must drive to the right side of the road). My account is not intended to cover these cases; but I do not think that these cases are tensed beliefs at all; tense here refers to a concept and not a linguistic category. A more interesting question is if the account can be generalized to cover instances of tensed beliefs that do not seem to involve an explicit temporal indexical notion like 'now' - if such beliefs can be meaningfully described as 'tensed'. This would imply the strong claim that all tensed beliefs are de re beliefs. The remarks of the next section can definitely be seen as leaning towards a positive answer to this question; but I think that this paper's conclusion does not rest on answering the question explicitly.
} 
(C') $\left(\mathrm{B}_{\mathrm{r}}\left(\mathrm{S},<\right.\right.$ now $>$, rStarts-at $\left(\right.$ class, $\left.\left.\left.\mathrm{y}_{\mathrm{n}}\right)\right\urcorner\right)$.

But this is not the only representation of (1) that could be true in the world. For instance when the res, i.e. the time involved in case 2 , is " 2.15 " or exactly the time of thought (C), we could have representations

$\left(\mathrm{C}^{*}\right)\left(\mathrm{B}_{\mathrm{r}}(\mathrm{S},<\right.$ time of S's belief $(\mathrm{C})>$, 「Starts-at(class, $\left.\left.\mathrm{y})\right\urcorner\right)$,

which would correspond to Smart's token-reflexivity claim extrapolated to the realm of thought and belief, or

$\left(\mathrm{C}^{* *}\right)\left(\mathrm{B}_{\mathrm{r}}(\mathrm{S},<2.15>\right.$, rStarts-at(class, $\left.\left.\mathrm{y})\right\urcorner\right)$,

which would correspond to a date-analysis of tenses.

In contrast, when $\mathrm{S}$ has a belief such as the belief that

(CD) the class is starting at 2.15

we could represent what $S$ believes as

(CD') ( $\mathrm{B}_{\mathrm{d}}(\mathrm{S}$, rStarts-at(class, “2.15") $)$ ).

Here $\mathrm{B}_{\mathrm{d}}$ represents de dicto belief. The idea is that we could give a description of $(\mathrm{C})$ that avoids mentioning A-notions. As per Mellor's and Smart's wishes, we have such a description (one of either $\mathrm{C}^{\prime}, \mathrm{C}^{*}$ or $\mathrm{C}^{* *}$ ) that uses only B-notions. If in the case of spatial perception (y) is an indexical that points in space, in this case it is an indexical that points in time. In all cases, it is just a placeholder to pick out the correct time, and it does not need to have an explicit descriptive sense associated with it. Moreover, the analysis shows that, like Burge, we can differentiate between beliefs $(\mathrm{C})$ and $\left(\mathrm{C}^{\prime}\right)$ without needing to posit A-facts or A-times.

However, the issue is not yet explained fully. It seems like the way we acquire a 'now' belief we would express with $(\mathrm{C})$ is different somehow from the way we acquire the beliefs in cases $\left(\mathrm{C}^{*}\right)$ or $\left(\mathrm{C}^{* *}\right)$. In these cases, we also have demonstratives that point in time, but they may not have the same explanatory role. For instance $\left(\mathrm{C}^{* *}\right)$ could describe a case where $\mathrm{S}$ points at a clock on the wall showing " 2.15 " and believes that "the class starts at that time". In this case it is not necessary that he would start running; he might not realize that the class is starting now. So the demonstrative involved in case (C) can only be accurately described by $\mathrm{y}_{\mathrm{n}}$ in case $\left(\mathrm{C}^{\prime}\right)$; only $\mathrm{y}_{\mathrm{n}}$ will have the precise action-explanatory role we are seeking. Burge's account shows some promise, but we have to show how we can individuate between free variables with different explanatory roles.

\section{4.}

This paper's modest proposal is that in order to explain exactly what this 'now-ish' indexical element is (and thus to fully explain human thought and action in cases 14), we might have to move away from epistemology to belief theory. If we keep the formalization and manage to explain the indexical element involved in it we should have a solution to the problem.

A possible explanation of our cases could be formed by borrowing the concept of an 'egocentric index' that is now quite often used in psychological and philosophical accounts of perception, vision and even self-knowledge. According to the way the term is used in the literature, humans and many other lower organisms have at least one spatial egocentric index in vision that has the perceiver as the origin of vision's spatial representational framework. Its function is to map perceived objects in spatial 
relation to the perceiver (for example, to the left). The index can be characterized as non-conceptual; there is actually evidence that lower animals have it. ${ }^{17}$ If the index is usefully employed in explaining case 3 (the 'here' thought arising from a perception instance) then we can posit the existence of a temporal index to explain cases 1 and 2. In case 3 the index points in space. In cases 1 and 2 a difference index points in time. Similarly to the spatial case in visual perception, the temporal index maps events in relation to the perceiver's temporal position (for example, before or after). Naturally, there is a big difference between indexical elements in perceptual contents on the one hand and full concepts on the other. But if the fully fledged 'here' concept is related to the spatial egocentric index then the fully fledged 'now' concept is related to the temporal egocentric index. We can spell out the similarity in the following way:

Spatial story: There is experimental evidence that suggests vision's egocentric index is related to actions in an instinctual manner. When a large object moves speedily toward the perceiver's position, the representation is immediately associated with motivation to get out of the way. It is a feature (maybe evolutionary) of our (and lower organisms') constitution that this happens in perception instances.

Temporal story: As we perceive things happening in close proximity to our bodies, we perceive things happening in close temporal proximity to our bodies. When a large object moves speedily toward the perceiver's position at a time close enough to the perceiver's temporal position, the representation is immediately associated with motivation to get out of the way. It is a feature of our constitution that this happens in perception.

This analogy between the spatial and temporal cases seems to me to capture an important similarity between 'now'-thoughts and 'here'-thoughts. It might be puzzling however to someone who does not share the same intuitions; someone who might try to argue that the temporal case differs significantly from the spatial case. Here is one way to form this claim: "It seems that objects (or events) at a spatial distance can still be perceived; but objects (or events) at a temporal distance cannot. An event that is sometime after or before now is not, it would seem, perceived. It is not clear, therefore, that a temporal index could be the same sort of thing as the spatial index". ${ }^{18}$

I think that there are two ways to face this problem. First, it is not so controversial to claim that objects (or events) at a temporal distance can be at least observed by a perceiver. Every night we observe stars in the sky (things) or planets moving (events) that usually are at a considerable temporal distance from us. Indeed, it seems that any perception instance is at least in some minimal degree removed from the time of the events perceived. It is true that we are experiencing events as happening at the same time as now. But this is purely a phenomenological feature that need not apply to our physical constitution.

\footnotetext{
${ }^{17}$ Burge (2003): An egocentric index for instance figures in memories of animals that cache food; even in perceptual representations of lower animals such as insects. There is actually evidence that such animals also retain in memory the time of the act of caching (Tulving 1983). Even if, as Markos Valaris has indicated to me, this does not provide any obvious proof of our having a similar non-conceptual index, the possibility of the two mechanisms sharing important characteristics seems quite a strong one to me.

18 The anonymous referee has offered this plausible objection.
} 
If this reply is not accepted, we can offer a modification of this theory (that may even be essential for alternative reasons). The modification would follow the idea that things in the world do not have separate spatial and temporal locations; they just have one kind of locations: spatiotemporal ones. If this is true, then maybe we could reform this chapter's sketch and describe a unique spatiotemporal index that would explain cases involving both 'here' and 'now'. Since this needs some experimental data however, I am leaving it aside for the moment as a promising possibility

I am pretty confident that this analogy is a promising first step. However, in an intuitive way cases 1-3 do not involve such an instinctual action; indeed the beliefs I entertain seem to be results of some kind of deliberation. How can we accommodate this? A first answer is the following:

The naïve view: A 'here' or 'now' thought is based on a conceptual reflection on a non-conceptual perception instance. ${ }^{19}$

For instance, my thought (L) in case 3 is a very primitive conceptual reflection on the perception episode that occurred when I saw the Beverly Hills sign. The concept 'here' is a complex notion that is based on reflection on perception instances; instances that apply the s-index. In this way the s-index can be seen as the primitive nonconceptual base of the concept 'here'; what might be called 'the phylogenic ancestor' of the fullyfledged concept. Similarly, in temporal cases, the concept 'now' is a complex notion that is based on reflection on perception instances -and they apply the temporal egocentric index. In this way the concept 'now' is the conceptual heir of the t-index.

Even if this treatment of tensed beliefs involved in Prior problems is still relatively raw, there is an obvious first objection that a more detailed analysis should take care of. ${ }^{20}$ The source of the objection I have in mind is the strong connection I am attempting to draw between perception instances and tensed beliefs. One might attempt to object by doubting the existence of such a strong link, for instance by imagining a subject with extreme deficiencies in perception having tensed beliefs. It might not be far-fetched to think of the following

Case 5: Bill is raised in an insulated environment without any changes in conditions that would lead him to act in a timely manner. Consequently, he never develops a response mechanism to external stimuli; for instance he is never chased by a tiger to run away. Even if Bill has an egocentric index, he does not use it in the manner required for forming tensed beliefs.

Case 5 would go against the naïve view in the following direct manner: Bill never has a perceptual thought incorporating the temporal egocentric index. As a consequence, and if the naïve theory is correct, Bill will not possess the concept of the present or indeed any concept of tense (since tenses in this account are

\footnotetext{
${ }^{19}$ I am calling it a "naïve" view because I am aware that it might prove too general to explain the whole story adequately. For that we probably need to look at what McDowell (1994, p.89), talking about perception, calls our "second nature". For this paper this would mean the way we learn to use the concept of 'now'. This could be done by examining what developmental psychology says about the issue, or by adopting Richard's (2003) ingenious idea about tacitly grasping the functional role of the concept. Unfortunately giving a story about this issue would exceed the proposed length of this paper.

${ }^{20}$ For this section I am indebted to Michael Tooley and Kevin Falvey.
} 
explained through the concept of the present). Not only will Bill never be able to communicate with us, he will never be able to have any tensed beliefs. But this should not be a plausible result when we are discussing such a case, the objector would continue. What if Bill is taught to use tensed verbs or the term 'now' in language by learning its semantic properties, for instance by learning that it always names the time of the utterance or that it has a fully spelled-out Kaplanian character? If this is possible, then Bill could acquire tensed beliefs even though they would not be connected to his unused egocentric index. Hence, the analysis I gave of what it is for Bill to have a tensed thought will be incorrect.

I think that the correct response to this case would be to bite the bullet and accept that Bill does not have any tensed beliefs and that he will never acquire them without perception instances that will token his 'now-ish' indexical element. However, it looks as though the bullet we are biting is entirely harmless. This could become obvious when we consider what it actually means for Bill to never have any perception-based thoughts. Not only should Bill be disconnected visually from his environment; he should be disconnected from any part of the external world and barred from any application of his senses. He cannot see his own limbs or hear any sounds or even have a response to any stimuli. In fact, we would have to suppose that Bill lacks any propriocentric or kinesthetic perceptions; and, if introspection is a form of perception, we might be forced to even assume that he lacks any introspective experiences. ${ }^{21}$ Why would we insist in that case that Bill would be able to have any thought that could be reasonably characterized as a belief, much more a tensed belief?

What is more pertinent, the second part of the objector's case shall not concern us at all: Bill can never be taught to use language as teaching requires a teacher and Bill will never be able to hear or interact with her (or "him" or even "it" in the case of a Matrix-like computer program) in any way. For the case to prove the implausibility of my account it would need something like an extremely convoluted brain in a vat case $^{22}$ : Bill would be a person who could form thoughts and beliefs and engage in rational thought without ever having any kind of veridical experience. But even in this extreme scenario Bill's tensed beliefs can be explained by pointing to Bill's apparent experiences. For instance, in a normal description of the case there is room for a lab-induced activation of his perception mechanism which could give us the elementary thoughts we need. In the absence of such an activation however, I think that Bill's deficiencies would be so radical that Bill cannot be deemed able to perform any actions in an agentive way. If this is true Bill cannot ever be involved in a Prior case that requires thought and corresponding agentive action; and this turn of events would immediately remove the main source of Smart's troubles.

To sum up: I think we have the first steps towards explaining the 'now' beliefs required for Mellor's account of what happens in Prior cases. A 'now' belief is a de $r e$ belief that can be syntactically analyzed by something like Burge's logical form $\left(1^{\prime}\right)$ and is based on a conceptual reflection on a perception instance. I think that this

\footnotetext{
${ }^{21} \mathrm{I}$ am indebted to the anonymous referee for suggesting the argument in the last sentence.

22 There might be some problems if a more extreme case is used; the Cartesian evil demon scenario. I will not deal with such a case here, first because I find its conceivability very strenuous, and second because I believe that we can follow a similar strategy against both the Cartesian and the brain-in-a-vat case.
} 
explanation adequately deals with the Prior problem. The actions in Prior cases are caused by 'now' beliefs de re. Moreover, we have the notion of a natural egocentric index that could explain how we acquire correct 'now' beliefs and how to individuate between different kinds of indexical elements. ${ }^{23}$ The important thing to note is that we have an explanation of all the relevant facts that avoids mentioning any possible A-facts: in the discussion so far we have used only B-notions. Hence, neither our syntactical analysis of 'now' beliefs nor the psychological explanation of their emergence and function can be appropriated by the A-theorist to support McTaggart's (M1). Moreover, we have made a first step in revealing the 'hidden anthropocentricity' required for Smart's (S1) and a successful refutation of (M1) without basing the argument in analyzing ordinary language: if the beliefs involved in Prior cases emerge through the earlier application (through a perceptual instance) of the non-conceptual human temporal index, it is no wonder that A-notions appear in human thought and utterance. What is important is that they do not feature in any description of the world as it is. I think Smart would be particularly pleased.

Acknowledgements I am grateful to Kevin Falvey, Markos Valaris, Richard Dietz, Nathan Oaklander and the participants and organizers of the "Time on Trial" conference for helpful comments and discussion on earlier versions of this paper. I am also indebted to an anonymous referee for his/her beneficial remarks.

Open Access This article is distributed under the terms of the Creative Commons Attribution Noncommercial License which permits any noncommercial use, distribution, and reproduction in any medium, provided the original author(s) and source are credited.

\section{References}

Beer, M. (1988). Temporal indexicals and the passage of time. The Philosophical Quarterly, 38, 158-164. doi: $10.2307 / 2219921$.

Burge, T. (1977). Belief De Re. Journal of Philosophy, 74, 338-362. doi:10.2307/2025871.

Burge, T. (2003). Memories and persons. The Philosophical Review, 112, 289-332. doi:10.1215/ 00318108-112-3-289.

Carnap, R. (1963). Intellectual autobiography. In P. A. Schilpp (Ed.), The philosophy of Rudolf Carnap. LaSalle, Illinois: Open Court.

Evans, G. (1982). The varieties of reference. Oxford: OUP.

Evans, G. (1981). Understanding demonstratives. In H. Parret \& J. Bouveresse (Eds.), Meaning and understanding (pp. 280-303). New York: De Gruyter.

Hyman, J. (1999). How knowledge works. The Philosophical Quarterly, 49, 433-451. 19.

\footnotetext{
${ }^{23}$ In the past months my attention has been focused on various accounts of indexicals that could be utilized in the place of the naïve view I indicated above. I feel obliged for instance to mention that the account of demonstratives in Evans (1981) and (1982) seems extremely close to the view sketched in this paper. The essential indexicality remains intact, there is an absence of a descriptive sense associated with the demonstratives, and certainly the demonstratives are directly linked with perception and spatiotemporal egocentricity. The difference is that Evans' indexicals are not mere placeholders as Burge proposes, but also have a Fregean sense. I would be entirely sympathetic to a treatment of tensed beliefs utilizing Evans' theory, if it is shown clearly that this Fregean sense does not make possible cases where the subject understands a specific indexical correctly ('grasps' the sense) but denotes the incorrect time; as such cases would give unexplained wrong results in Prior situations.
} 
Kaplan, D. (1989). Demonstratives. In J. Almog, J. Perry, \& H. Wettstein (Eds.), Themes from Kaplan (pp. 481-615). Oxford: UP.

McDowell, J. (1994). Mind and world. Cambridge, Mas.: Harvard University Press.

McTaggart, J. M. E. (1927). The nature of existence vol. Cambridge: II.

Mellor, D. H. (1998). Real time II. London: Routledge.

Oaklander, L. N. (1994). A defence of the new tenseless theory of time. In L. N. Oaklander \& Q. Smith (Eds.), The new theory of time. New Haven: Yale UP.

Perry, J. (1979). The problem of the essential indexical. Nous, 13, 3-21. doi:10.2307/2214792.

Perry, J. (2001). Knowledge, possibility \& consciousness. Cambridge: MIT Press.

Prior, A. N. (1959). Thank goodness that's over. Philosophy, 34, 12-17. doi:10.1017/S0031819100029685.

Richard, M. (2003). Objects of Relief. In A. Jokic (Ed.), Time, tense and reference. Cambridge: MIT Press.

Salmon, N. (2003). Tense and intension. In A. Jokic (Ed.), Time, tense and reference. Cambridge: MIT Press.

Smart, J. J. C. (1963). "The space-time world", in Metaphysics, contemporary readings, Ed. Michael Loux, Routledge, 2001

Smith, Q. (1993). Language and time. New York: Oxford University Press.

Tooley, M. (1997). Time. Tense and Causation: Oxford University Press.

Tulving, E. (1983). Episodic memory. Oxford University Press. 